\title{
FRACTURE THROUGH A SYNCHONDROSIS OF THE ANTERIOR ARCH OF THE ATLAS
}

\author{
YOSHIHIRO MIKAWA, RYO WATANABE, YOSHIKI YAMANO, KANJI ISHII
}

A four-year-old boy was playing on a slide when he fell, striking his head on the ground and hurting his neck. He held his head in the "cock-robin" position and examination revealed limited movement of the neck and paravertebral muscle spasm. A lateral radiograph showed subluxation of $\mathrm{Cl}$ on $\mathrm{C} 2$ (Fig. 1).

Halter traction was applied, and after a few days there was a normal range of flexion and rotation, but a further radiograph showed that the subluxation was unchanged. A CT scan revealed a fracture-separation through the synchondrosis on the left side of the anterior arch of the atlas, with widening of the atlanto-axial interval (Fig. 2). After three weeks of cervical traction, a cervicothoracic brace was applied and retained for two abnormal movement. At no time were there any abnormal neurological signs.

Discussion. In 1920, Jefferson reviewed 46 cases of fractures of the atlas, including four of his own. One of these, as well as cases reported by Marlin, Williams and Lee (1983), Galindo and Francis (1983), and Richards (1984) are the only six examples we could find in the literature of fractures of the atlas in children; none of them had an isolated fracture-separation of a synchondrosis of the anterior arch. According to Jefferson (1920), the injuries result from the vectors of forces transmitted through the occiput and cervical spine spreading laterally and causing fractures at the weakest points. It is recognised that apophyseal and epiphyseal areas are
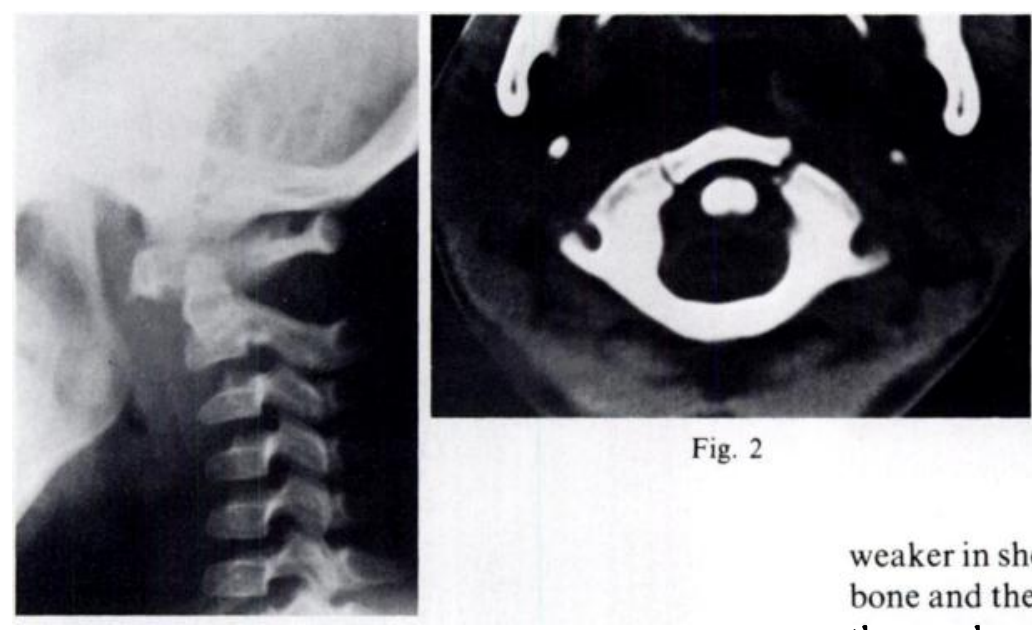

Fig. 2

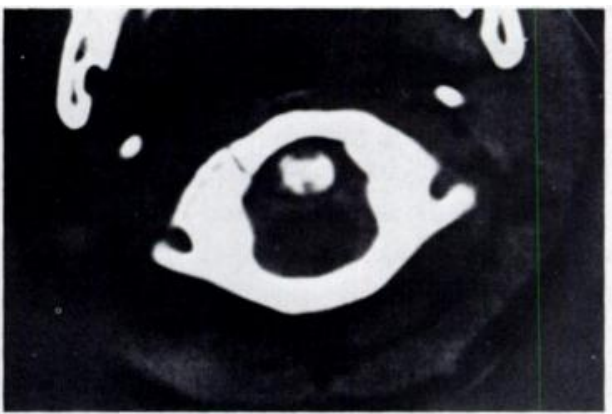

Fig.3
Fig. 1

months; at four months he had a normal range of movement except for extension. A new lateral film showed $5 \mathrm{~mm}$ of anterior displacement of $\mathrm{Cl}$ on $\mathrm{C} 2$, which is thought to be the upper limit in children. A repeat $C T$ scan showed complete healing of the fractureseparation through the synchondrosis (Fig. 3). At followup, the child had a normal range of neck movements; lateral flexion and extension radiographs showed no

Y. Mikawa, MD, Instructor

R. Watanabe, MD, Professor and Director

Y. Yamano, MD, Associate Professor

K. Ishii, MD, Assistant

Department of Orthopaedic Surgery, Kawasaki Medical School 577

Matsushima, Kurashiki, Okayama, Japan.

Correspondence to Mr Y. Mikawa.

(C) 1987 British Editorial Society of Bone and Joint Surgery 0301-620X/87/3R $17 \$ 2.00$ weaker in shear and torsion stresses than the surrounding bone and the weakest areas of $\mathrm{Cl}$ in a child could well be the synchondroses.

In our child spasm of the cervical muscles and limitation of neck movement made an open-mouth view very difficult to obtain. Tomography might have been helpful, but this also would have needed co-operation from the patient. A CT scan seems to be the investigation of choice and in our case it showed the fractureseparation described. The clinical course of our case suggests that fractures of the atlas in children have a good outcome.

\section{REFERENCES}

Galindo MJ Jr, Francis WR. Atlantal fracture in a child through congenital anterior and posterior arch defects: a case report. Clin Orthop 1983;178:220-2.

Jefierson G. Fracture of the atlas vertebra : report of four cases, and a review of those previously recorded. Br J Surg 1919-20;7:407-22.

Marlin AE, Williams GR, Lee JF. Jefferson fractures in children : case report. J Neurosurg 1983;58:277-9.

Richards PG. Stable fractures of the atlas and axis in children. $J$ Neurol Neurosurg Psychiatry 1984;47:781-3. 